\title{
HUBUNGAN DERAJAT KEPARAHAN KELAINAN PERIODONTAL DENGAN TRAUMATIK OKLUSI PADA PEMAKAI GIGI TIRUAN SEBAGIAN LEPASAN DI RSGM USU
}

\author{
Jevon Felim, Ariyani Dallmer \\ Departemen Prostodonsia \\ Fakultas Kedokteran Gigi, Universitas Sumatera Utara \\ Jalan Alumni No. 2 Kampus USU Medan 20155 \\ Email: jevonfelim@yahoo.com
}

\begin{abstract}
Abstrak
Gigi tiruan sebagian lepasan (GTSL) bertujuan untuk menggantikan gigi yang hilang serta jaringan pendukungnya, dapat dipasang dan dilepas sendiri oleh pemakainya. Jaringan periodontal mempunyai batas ambang dalam menahan tekanan oklusi, bila tekanan ini berlebihan dapat mencederai jaringan periodontal. Pasien diinstruksikan untuk menjaga kebersihan gigi tiruan dan gigi penyangga. Bila GTSL tidak dibersihkan dapat mengakibatkan akumulasi debris pada bagian gigi penyangga dan konektor minor, sehingga mengakibatkan terjadinya inflamasi gingiva. Penelitian ini merupakan penelitian deskriptif analitik dengan menggunakan rancangan penelitian cross sectional. Sampel pada penelitian ini adalah pasien yang membuat gigi tiruan sebagian lepasan di Rumah Sakit Gigi dan Mulut Universitas Sumatera Utara sejak bulan Juni 2014 sampai bulan Juli 2015 yang berjumlah 100 orang. Subjek penelitian dilakukan pemeriksaan klinis berupa pemeriksaan kelainan periodontal, traumatik oklusi dan oral hygiene. Subjek penelitian yang mengalami kelainan periodontal dibagi menjadi 4 kelompok derajat keparahan yaitu gingivitis sederhana, periodontal destruksi tahap awal, periodontal destruksi tahap mantap, dan penyakit pada tahap akhir. Hasil penelitian menunjukkan ada hubungan yang signifikan antara derajat keparahan kelainan periodontal (gingivitis sederhana, periodontal destruksi tahap awal, periodontal destruksi tahap mantap, dan penyakit pada tahap akhir) dengan traumatik oklusi dengan nilai $\mathrm{p}=0,011$.
\end{abstract}

Kata Kunci: GTSL, traumatik oklusi, kelainan periodontal, derajat keparahan

\section{PENDAHULUAN}

Edentulus telah lama dianggap sebagai bagian dari proses penuaan. Edentulus dapat disebabkan oleh kerusakan gigi, periodontitis, atau kecelakaan.Edentulus dapat menyebabkan estetik yang buruk, sehingga menimbulkan keinginan untuk mencari perawatan gigi agar mendapatkan penampilan yang lebih baik. Edentulus sebagian adalah hilangnya satu gigi hingga 15 gigi dalam satu rahang. ${ }^{1}$ Beberapa jenis perawatan yang dapat dilakukan adalahdengan gigi tiruan cekat, gigi tiruan cekat dukungan implan atau gigi tiruan sebagian lepasan. ${ }^{2}$ Gigi tiruan sebagian lepasan (GTSL) dibuat untuk menggantikan gigi yang hilang serta jaringan pendukungnya, dapat dipasang dan dilepas sendiri oleh pemakainya. ${ }^{3}$ Dalam pembuatan GTSL kita harus melewati beberapa tahap dimulai dari tahap rencana perawatan, perawatan klinis serta laboratorium dan tahap pemeliharaan. Di dalam tahap perawatan klinis dan laboratorium terdapat beberapa hal yang harus dilakukan oleh dokter gigi salah satunya adalah tahap pemasangan. Pada tahap pemasangan dilakukan penyesuaian oklusi dari gigi asli dengan gigi asli, anasir gigi tiruan dengan gigi asli, dan penyesuaian oklusi dari anasir gigi tiruan dengan anasir gigi tiruan menggunakan kertas artikulasi dan shim stock. $^{2}$

Oklusi merupakan salah satu aspek penting yang berperan besar dalam proses pengunyahan, menelan, serta berbicara. Oklusi secara sederhana dapat diartikan sebagai kontak antar gigi geligi bawah dengan gigi geligi atas. Kontak ini akan menghasilkan suatu tekanan yang kemudian diteruskan ke jaringan periodontal. Jaringan periodontal yang sehat meliputi sementum, ligamen periodontal, dan tulang alveolar, sebagai kesatuan fungsi unit atau organ. ${ }^{4}$ Jaringan ini merupakan jaringan pendukung dan mengelilingi gigi, berfungsi meredam tekanan oklusi yang diterima oleh gigi. Jaringan periodontal mempunyai batas ambang dalam menahan tekanan oklusi, bila tekanan ini berlebihan dapat mencederai jaringan periodontal. ${ }^{4}$ Kontak oklusi yang tidak tepat dapat menimbulkan masalah, salah satunya adalah penyakit periodontal. Oklusi yang tidak tepat ini biasanya ditimbulkan oleh tumpatan yang overhanging, protesa dengan desain yang kurang baik, kebiasaan bruxism, serta susunan gigi geligi yang tidak teratur. ${ }^{5}$ Kelainan periodontal dapat terjadi 6 bulan setelah terjadi traumatik oklusi. ${ }^{6}$ Trauma oklusal adalah suatu proses keseluruhan yang dikenal dengan traumatik oklusi yang menyebabkan 
terjadinya cedera pada jaringan pendukung, akibat gaya oklusal yang berlebihan. ${ }^{4} 7$ Traumatik oklusi akut dapat terjadi karena adanya faktor eksternal dan traumatik oklusi kronis dapat terjadi karena adanya faktor internal (prematur kontak). Traumatik oklusi kronis dibagi menjadi traumatik oklusi primer dan traumatik oklusi sekunder. ${ }^{4}$

Traumatik oklusi dapat diidentifikasi dengan menggunakan kertas artikulasi.Kertas artikulasi yang lebih tipis memiliki keakuratan yang lebih baik dibandingkan dengan kertas artikulasi yang tebal. Tanda yang terdapat pada gigi tersebut akan menjadi penentu terjadinya traumatik oklusi bila tanda tersebut lebih tebal dari tanda pada gigi lain, ataupun terdapat tanda pada daerah yang seharusnya tidak terjadi kontak pada saat oklusi. ${ }^{8}$ Traumatik oklusi juga dapat dideteksi dengan shim stock yang merupakan salah satu jenis indikator oklusi tipe kualitatif yang berfungsi dalam menentukan lokasi dan jumlah gigi yang berkontak. ${ }^{9-12}$

Pada tahap pemasangan GTSL, selain dilakukan pemeriksaan oklusi, pasien juga diberi penjelasan tentang cara yang benar untuk memakai dan melepaskan gigi tiruan dan diinstruksikan untuk menjaga kebersihan gigi tiruan dan gigi penyangga. Bila GTSL tidak dibersihkan dapat mengakibatkan akumulasi debris pada bagian gigi penyangga dan konektor minor, sehingga mengakibatkan terjadinya inflamasi gingiva. Pasien diinstruksikan melakukan pemeriksaan berkala setiap 6 bulan sekali. ${ }^{2}$ GTSL mendapat dukungan dari gigi yang tersisa, beberapa penelitian telah mempelajari apakah kasus tersebut memiliki efek untuk kesehatan periodontal, seperti akumulasi plak, inflamasi gingiva, mobiliti, kedalaman poket, dan kehilangan perlekatan. ${ }^{16}$

\section{METODE}

Penelitian ini merupakan penelitian deskriptif analitik menggunakan rancangan penelitian cross sectional.Sampel pada penelitian ini merupakanpasien yang membuat gigi tiruan sebagian lepasan di Rumah Sakit Gigi dan Mulut Universitas Sumatera Utara sejak bulan Juni 2014 sampai bulan Juli 2015 yang berjumlah 100 orang.

Subjek penelitian diintruksikan untuk membuka mulut lebar dan melepas GTSL. Jumlah dan letak gigi penyangga GTSL dan anasir diberi tanda pada lembar kuisioner untuk dilakukan pemeriksaan.Peneliti melakukan pemeriksaan klinis terhadap keadaan periodontal dari gigi tersebut, dan dilihat apakah terdapat resesi gingiva.Ada tidaknya resesi gingiva ditentukan dari keadaan atau kondisi marginal gingiva yang lebih apikal dari cementoenamel junction (CEJ) dan biasanya disertai dengan terbukanya permukaan akar gigi.Kemudian peneliti memperhatikan jaringan periodontal yang mengalami inflamasi, apakah inflamasi tersebut hanya pada sebagian daerah atau mengelilingi gigi. Lalu peneliti melakukan pemeriksaan mobiliti dengan cara mengapit gigi menggunakan satu instrumen dental dan satu jari telunjuk operator, kemudian gigi digerakkan kearah facial-lingual. $^{6}$ Jika terlihat pergerakan/kegoyangan, maka gigi tersebut mengalami mobiliti.

Hasil pemeriksaan dimasukkan ke tabel indeks periodontal Russel untuk dihitung derajat keparahannya.Skor Indeks Periodontal pada seseorang dihitung dengan menjumlahkan skor dari setiap gigi yang diperiksa, lalu dibagi dengan jumlah gigi yang diperiksa.

Subjek penelitian yang mengalami kelainan periodontal dilanjutkan dengan pemeriksaan traumatik oklusi, sedangkan pasien yang tidak mengalami kelainan periodontal dieksklusi sebagai sampel.

Peneliti memposisikan kertas artikulasi menggunakan forcep miller (Penjepit kertas artikulasi) pada dataran oklusal pasien, lalu memposisikan pasien untuk melakukan oklusi sentrik.Kemudian kertas artikulasi dikeluarkan untuk melihat tanda yang tertinggal di permukaan oklusal gigi.Apabila terdapat tanda yang menyimpang maka subjek tersebut dilakukan pemeriksaan lanjutan. Setelah itu, letakkan shim stock pada daerah yang mengalami traumatik dengan menggunakan forcep. Instruksikan pasien untuk mengoklusikan gigi pada posisi interkuspal maksimum. Cara ini disebut dengan "close and hold". Klinisi menarik shim stock diantara gigi yang sedang dioklusikan ke arah bukal. Klinisi mengamati seberapa kuat gigi yang sedang dioklusikan tersebut menahan shim stock pada saat shim stock ditarik ke arah bukal. Daerah yang menahan tersebut menandakan bahwa daerah tersebut mengalami traumatik oklusi.

Dilakukan Pemeriksaan plak dengan menggunakan indeks Loe and Silness.Penilaian plak indeks dilakukan dengan menggunakan kaca mulut dan sonde setelah gigi dikeringkan. ${ }^{34}$ Pengukuran pada gigi dilakukan pada empat sisi, yaitu : distovestibular, vestibular, mesiovestibular dan oral. ${ }^{17}$

Data yang bersifat deskriptif akan disajikan dalam tabel frekuensi deskriptif (analisis univariat). Data yang bersifat analitik, dilakukan uji chi-square untuk melihat ada tidaknya hubungan traumatik oklusi dengan kelainan periodontal.

\section{HASIL}

Pemeriksaan traumatik oklusi dilakukan menggunakan articulating paper dengan ketebalan $20 \mu \mathrm{m}$ dan shim stock dengan ketebalan $8 \mu \mathrm{m}$. Di tahun 1993 Anderson dkk (dikutip dari Panigrahi D, 2015 dan Sharma A, 2013) melakukan penelitian untuk membandingkan keakuratan antara kertas artikulasi dan shim stock yang dievaluasi melalui kontak oklusal dalam posisi interkuspasi. Hasilnya menunjukkan shim stock lebih akurat dibandingkan kertas artikulasi. ${ }^{11,12}$ Shim stock tidak memberikan tanda pada gigi yang mengalami traumatik oklusi maka dalam pemakaiannya shim stock dikombinasikan dengan penggunaan kertas artikulasi. ${ }^{14}$ Menurut Reiber dkk tahun 1989 (dikutip dari Qadeer S, 2015), shim stock merupakan alat indikator kualitatif yang paling tipis dengan ketebalan $0,2,6,8$, dan 12 $\mu \mathrm{m}^{13}$ sehingga akan memberikan hasil yang lebih akurat jika dibandingkan dengan kertas artukulasi. 
Berdasarkan hasil pengumpulan data, sebanyak 5 pasien $(12,82 \%)$ mempunyai $\mathrm{OH}$ baik, 15 pasien $(38,46 \%)$ mempuyai $\mathrm{OH}$ sedang, dan 19 pasien $(48,72 \%)$ mempunyai $\mathrm{OH}$ buruk. (Tabel 1)

Tabel 1. Prevalensi Oral Hygiene pada pemakai GTSL di RSGM USU dari bulan Juni 2014 sampai bulan Juli 2015.

\begin{tabular}{|c|c|c|}
\hline \multirow{2}{*}{$\begin{array}{c}\text { Oral } \\
\text { Hygiene }\end{array}$} & \multicolumn{2}{|c|}{ Jumlah } \\
\cline { 2 - 3 } & $\mathrm{n}$ & $\%$ \\
\hline Baik & 5 & 12,82 \\
\hline Sedang & 15 & 38,46 \\
\hline Buruk & 19 & 48,72 \\
\hline Jumlah & 39 & 100 \\
\hline
\end{tabular}

Berdasarkan pengukuran indeks $O H$ dapat diketahui distribusi 39 pasien kelainan periodontal ke dalam 3 kategori yaitu $\mathrm{OH}$ baik, $\mathrm{OH}$ sedang dan $\mathrm{OH}$ buruk. Dalam kategori $\mathrm{OH}$ baik, pasien yang mengalami gingivitis sederhana adalah sebanyak 4 pasien $(10,26 \%)$, tidak ada yang mengalami periodontal destruksi tahap awal dan penyakit pada tahap akhir, sebanyak 1 pasien $(2,57 \%)$ yang mengalami periodontal destruksi tahap mantap.

Dalam kategori $\mathrm{OH}$ sedang, pasien yang mengalami gingivitis sederhana adalah sebanyak 2 pasien $(5,13 \%), 9$ pasien $(23,08 \%)$ yang mengalami periodontal destruksi tahap awal, 3 pasien $(7,69 \%)$ mengalami periodontal destruksi tahap mantap, 1 pasien $(2,57 \%)$ yang mengalami penyakit pada tahap akhir.

Dalam kategori $\mathrm{OH}$ buruk, pasien yang mengalami gingivitis sederhana adalah sebanyak 3 pasien $(7,69 \%), 5$ pasien $(12,82 \%)$ mengalami periodontal destruksi tahap awal, 8 pasien $(20,51 \%)$ yang mengalami periodontal destruksi tahap mantap sedangkan 3 pasien $(7,69 \%)$ yang mengalami penyakit pada tahap akhir. (Tabel 2)

Tabel 2. Prevalensi Derajat keparahan Kelainan Periodontal pada Pemakai GTSL berdasarkan indeks OH di RSGM USU dari bulan Juni 2014 sampai Bulan Juli 2015.

\begin{tabular}{|c|c|c|}
\hline \multirow{2}{*}{$\begin{array}{c}\text { Traumatik } \\
\text { Oklusi }\end{array}$} & \multicolumn{2}{|c|}{ Jumlah } \\
\cline { 2 - 3 } & $\mathrm{n}$ & $\%$ \\
\hline Ada & 36 & 92,31 \\
\hline Tidak Ada & 3 & 7,69 \\
\hline Jumlah & 39 & 100 \\
\hline
\end{tabular}

Pemeriksaan traumatik oklusi dilakukan melalui pemeriksaan klinis menggunakan kertas artikulasi dan Shim Stock. Berdasarkan hasil pengumpulan data, sebanyak 36 pasien $(92,31 \%)$ mengalami traumatik oklusi sedangkan 3 pasien $(7,69 \%)$ tidak mengalami traumatik oklusi. (Tabel 3)
Tabel 3. Prevalensi traumatik oklusi pada pemakai GTSL di RSGM USU dari bulan Juni 2014 sampai bulan Juli 2015.

\begin{tabular}{|c|c|c|c|c|c|c|c|c|c|c|}
\hline \multirow{2}{*}{$\begin{array}{c}\text { Oral } \\
\text { Hygie } \\
\text { ne }\end{array}$} & \multicolumn{10}{|c|}{ Kelainan Periodontal } \\
\cline { 2 - 12 } & $\begin{array}{c}\text { Gingivitis } \\
\text { Sederhana }\end{array}$ & \multicolumn{2}{|c|}{$\begin{array}{c}\text { Destruksi } \\
\text { Tahap Awal }\end{array}$} & $\begin{array}{c}\text { Destruksi } \\
\text { Tahap } \\
\text { Mantap }\end{array}$ & $\begin{array}{c}\text { Penyakit } \\
\text { Pada } \\
\text { Tahap } \\
\text { Akhir }\end{array}$ & \multicolumn{2}{|c|}{ Jumlah } \\
\cline { 2 - 13 } & $\mathrm{n}$ & $\%$ & $\mathrm{n}$ & $\%$ & $\mathrm{n}$ & $\%$ & $\mathrm{n}$ & $\%$ & $\mathrm{n}$ & $\%$ \\
\hline Baik & 4 & 10,26 & 0 & 0 & 1 & 2,57 & 0 & 0 & 5 & 12,82 \\
\hline $\begin{array}{c}\text { Sedan } \\
\text { g }\end{array}$ & 2 & 5,13 & 9 & 23,08 & 3 & 7,69 & 1 & 2,57 & 15 & 38,46 \\
\hline Buruk & 3 & 7,69 & 5 & 12,82 & 8 & 20,51 & 3 & 7,69 & 19 & 48,72 \\
\hline Jumlah & 9 & 23,08 & 14 & 35,9 & 12 & 30,77 & 4 & 10,26 & 39 & 100 \\
\hline
\end{tabular}

Dari 36 pasien yang mengalami traumatik oklusi kemudian diklasifikasikan kedalam traumatik oklusi statis, traumatik oklusi dinamis serta traumatik oklusi statis dan dinamis.

Dari 36 pasien yang mengalami traumatik oklusi, 26 pasien $(72,22 \%)$ mengalami traumatik oklusi pada oklusi statis dan 10 pasien $(27,78 \%)$ tidak mengalami traumatik oklusi pada oklusi statis, 31 pasien $(86,11 \%)$ mengalami traumatik oklusi pada oklusi lateral dan 5 pasien $(13,89 \%)$ tidak mengalami traumatik oklusi pada oklusi lateral dengan rincian sebanyak 11 pasien $(30,56 \%)$ mengalami traumatik oklusi pada sisi working, 14 pasien $(38,89 \%)$ mengalami traumatik oklusi pada sisi balancing,dan 6 pasien $(16,67 \%)$ mengalami traumatik oklusi pada sisi working dan sisi balacing, 21 pasien $(58,33 \%)$ mengalami traumatik oklusi pada oklusi anteroposterior dan 15 pasien $(41,66 \%)$ tidak mengalami traumatik oklusi pada oklusi anteroposterior, serta 25 pasien $(69,44 \%)$ mengalami traumatik oklusi pada oklusi statis dan dinamis dan 11 pasien (30,56\%) tidak mengalami traumatik oklusi pada oklusi statis dan dinamis. (Tabel 4)

Tabel 4. Prevalensi traumatik oklusi pada pemakai GTSL di RSGM USU dari bulan Juni 2014 sampai bulan Juli 2015 berdasarkan oklusi statis dan oklusi dinamis.

\begin{tabular}{|c|c|c|c|c|c|c|}
\hline \multirow{2}{*}{$\begin{array}{c}\text { Pemeriksaan Traumatik } \\
\text { Oklusi }\end{array}$} & \multicolumn{2}{|c|}{ Ada } & \multicolumn{2}{|c|}{ Tidak Ada } & \multicolumn{2}{|c|}{ Jumlah } \\
\hline & $\mathrm{n}$ & $\%$ & $\mathrm{n}$ & $\%$ & $\mathrm{n}$ & $\%$ \\
\hline Oklusi Statis & 26 & 72,22 & 10 & 27,78 & 36 & 100 \\
\hline Oklusi Dinamis & & & & & & \\
\hline Lateral & 31 & 86,11 & 5 & 13,89 & 36 & 100 \\
\hline - Working Side & 11 & 30,56 & & & & \\
\hline - Balancing Side & 14 & 38,89 & & & & \\
\hline Keduanya & 6 & 16,67 & & & & \\
\hline Anteroposterior & 21 & 58,33 & 15 & 41,66 & 36 & 100 \\
\hline \begin{tabular}{|ll} 
3. & Oklusi Statis dan \\
& Dinamis \\
\end{tabular} & 25 & 69,44 & 11 & 30,56 & 36 & 100 \\
\hline
\end{tabular}

Dari 36 pasien yang mengalami traumatik oklusi, didapati bahwa 7 pasien $(19,95 \%)$ mengalami gingivitis sederhana, 13 pasien $(33,33 \%)$ mengalami periodontal destruksi tahap awal, 12 pasien $(30,77 \%)$ mengalami periodontal destruksi tahap mantap dan 4 pasien $(10,26 \%)$ mengalami penyakit pada tahap akhir, sedangkan pada pasien yang tidak mengalami traumatik oklusi didapati bahwa 2 pasien $(5,13 \%)$ mengalami gingivitis sederhana, 1 pasien $(2,57 \%)$ mengalami periodontal destruksi tahap awal, dan tidak ada pasien 
yang mengalami periodontal destruksi tahap mantap maupun mengalami penyakit pada tahap akhir. (Tabel 5)

Tabel 5. Prevalensi Derajat keparahan Kelainan Periodontal pada PemakaiGTSL berdasarkan Traumatik Oklusi di RSGM USU dari Bulan Juni 2014 sampai Bulan Juli 2015.

\begin{tabular}{|c|c|c|c|c|c|c|c|c|c|c|}
\hline \multirow{4}{*}{$\begin{array}{c}\text { Traumatik } \\
\text { Oklusi }\end{array}$} & \multicolumn{10}{|c|}{ Kelainan Periodontal } \\
\hline & \multirow{2}{*}{\multicolumn{2}{|c|}{$\begin{array}{l}\text { Gingivitis } \\
\text { Sederhana }\end{array}$}} & \multirow{2}{*}{\multicolumn{2}{|c|}{$\begin{array}{c}\text { Destruksi } \\
\text { Tahap Awal }\end{array}$}} & \multirow{2}{*}{\multicolumn{2}{|c|}{$\begin{array}{c}\text { Destruksi } \\
\text { Tahap } \\
\text { Mantap }\end{array}$}} & \multirow{2}{*}{\multicolumn{2}{|c|}{$\begin{array}{l}\text { Penyakit Pada } \\
\text { Tahap Akhir }\end{array}$}} & \multirow{2}{*}{\multicolumn{2}{|c|}{ Jumlah }} \\
\hline & & & & & & & & & & \\
\hline & $\mathrm{n}$ & $\%$ & $\mathrm{n}$ & $\%$ & $\mathrm{n}$ & $\%$ & $\mathrm{n}$ & $\%$ & $\mathrm{n}$ & $\%$ \\
\hline Ada & 7 & 19,95 & 13 & 33,33 & 12 & 30,77 & 4 & 10,26 & 36 & 92,31 \\
\hline $\begin{array}{l}\text { Tidak } \\
\text { Ada }\end{array}$ & 2 & 5,13 & 1 & 2,57 & 0 & 0 & 0 & 0 & 3 & 7,69 \\
\hline Jumlah & 9 & 23,08 & 14 & 35,9 & 12 & 30,77 & 4 & 10,26 & 39 & 100 \\
\hline
\end{tabular}

Berdasarkan penelitian ini, pasien yang mengalami gingivitis sederhana dan mengalami traumatik oklusi 7 pasien $(17,95 \%), 2$ pasien $(5,13 \%)$ mengalami gingivitis sederhana dan tidak mengalami traumatik oklusi. Pasien yang mengalami periodontal destruksi tahap awal dan mengalami traumatik oklusi adalah 13 pasien $(33,33 \%), 1$ pasien $(2,56 \%)$ mengalami periodontal destruksi tahap awal dan tidak mengalami traumatik oklusi. Pasien yang mengalami periodontal destruksi tahap mantap dan mengalami traumatik oklusi adalah 12 pasien $(30,77 \%)$, tidak ada pasien $(0 \%)$ mengalami periodontal destruksi tahap mantap dan tidak mengalami traumatik oklusi. Pasien yang mengalami penyakit pada tahap akhir dan mengalami traumatik oklusi adalah 4 pasien $(10,26 \%)$, tidak ada pasien $(0 \%)$ yang mengalami penyakit pada tahap akhir dan tidak mengalami traumatik oklusi.

Berdasarkan traumatik oklusi diperoleh frekuensi pasien baik yang mengalami gingivitis sederhana, periodontal destruksi tahap awal, periodontal destruksi tahap mantap, maupun penyakit pada tahap akhir paling tinggi terdapat pada pasien yang mengalami traumatik oklusi dengan gejala periodontal destruksi tahap awal sebanyak 13 pasien $(33,33 \%)$, sedangkan frekuensi paling rendah terdapat pada pasien yang tidak mengalami traumatik oklusi dengan gejala periodontal destruksi tahap mantap dan penyakit pada tahap akhir dengan 0 pasien (0\%). Uji Chi-Squaremenunjukkan ada hubungan yang signifikan antara derajat keparahan kelainan periodontal (gingivitis sederhana, periodontal destruksi tahap awal, periodontal destruksi tahap mantap, dan penyakit pada tahap akhir) dengan traumatik oklusi dengan nilai $\mathrm{p}=$ 0,011. (Tabel 6)

Tabel 6. Hubungan antara derajat keparahan kelainan periodontal dengan traumatik oklusi pada pemakai GTSL diRSGM USU dari bulan Juni 2014 sampai bulan Juli 2015.

\begin{tabular}{|c|c|c|c|c|c|c|}
\hline \multirow{2}{*}{$\begin{array}{c}\text { Kelainan } \\
\text { Periodontal }\end{array}$} & \multicolumn{4}{|c|}{ Traumatik Oklusi } & \multirow{2}{*}{ Jumlah } & \multirow{2}{*}{$\mathrm{p}$} \\
\cline { 2 - 5 } & \multicolumn{2}{|c|}{ Ada } & \multicolumn{2}{|c|}{ Tidak Ada } & \\
\cline { 2 - 6 } & $\mathrm{n}$ & $\%$ & $\mathrm{n}$ & $\%$ & & \\
\hline $\begin{array}{c}\text { Gingivitis } \\
\text { Sederhana }\end{array}$ & 7 & 17,95 & 2 & 5,13 & 9 & \\
\hline $\begin{array}{c}\text { Destruksi } \\
\text { Tahap Awal }\end{array}$ & 13 & 33,33 & 1 & 2,56 & 14 & \multirow{2}{*}{$0,011^{*}$} \\
\hline Destruksi & 12 & 30,77 & 0 & 0 & 12 & \\
\hline
\end{tabular}

\begin{tabular}{|c|c|c|c|c|c|c|}
\hline Tahap Mantap & & & & & & \\
\hline $\begin{array}{c}\text { Penyakit pada } \\
\text { Tahap Akhir }\end{array}$ & 4 & 10,26 & 0 & 0 & 4 & \\
\hline Jumlah & 36 & 92,31 & 3 & 7,69 & 39 & \\
\hline
\end{tabular}

* : Terdapat hubungan yang signifikan dimana nilai $\mathrm{p}<0,05$

\section{PEMBAHASAN}

Penelitian ini menunjukkan bahwa semakin buruk $\mathrm{OH}$ seseorang maka akan menyebabkan semakin parahnya penyakit periodontal yang diderita. Penyakit periodontal merupakan penyakit infeksi diawali oleh bakteri yang terakumulasi dalam plak sehingga menyebabkan peradangan pada gingiva.Plak pada margin gingiva jika tidak dihilangkan secara cermat akan menjadi keras. Plak yang mengeras ini disebut kalkulus yang tidak dapat dihilangkan dengan menggunakan sikat gigi ataupun benang gigi, namun diperlukan bantuan dokter gigi untuk menghilangkannya.Pasien dengan penyakit periodontal sering mengabaikan penyakit tersebut karena sakit pada giginya tidak mengganggu aktivitas, sehingga proses penyakit periodontal akan terus berlanjut jika tidak ditangani.

Pada penelitian ini hampir seluruh pemakai GTSL yang mengalami traumatik oklusi statis memiliki traumatik oklusi dinamis, tabel 2 menunjukkan jumlah pemakai GTSL yang mengalami traumatik oklusi statis adalah sebanyak 26 pasien, sedangkan pemakai GTSL yang mengalami traumatik oklusi statis dan dinamis adalah 25 pasien. Tipton dan Rinchuse (1991) menyatakan bahwa tidak adanya hubungan antara oklusi statis dan juga dinamis, namun menurut penelitian Al-Hiyasat dan AbuAlhaijah (2004) menyatakan bahwa terdapat hubungan antara traumatik oklusi statis dan dinamis. Hubungan dari traumatik oklusi statis dan dinamis diuji berdasarkan Klas dari hubungan gigi, canine guidance, dan group function. Terdapat beberapa faktor (Multifaktorial) yang mempengaruhi derajat keparahan kelainan periodontal, traumatik oklusi merupakan salah satu faktor predisposisi terjadinya kelainan periodontal. ${ }^{18}$

Hasil Uji Chi-Square menunjukkan adanya hubungan antara kelainan periodontal (gingivitis sederhana, periodontal destruksi tahap awal, periodontal destruksi tahap mantap dan penyakit pada tahap akhir) dengan traumatik oklusi dengan nilai $\mathrm{p}=0,011$. Hal ini dapat terjadi disebabkan karena pada kondisi non patologis, jaringan periodontal akan meresopsi tekanan yang datang searah dengan aksial gigi. Perubahan arah tekanan akan menyebabkan kerusakan jaringan karena jaringan periodontal tidak dapat menahan tekanan horizontal. Tipe injuri ini adalah akibat dari tekanan oklusal dari luar sepanjang aksis gigi yang disebut dengan traumatik oklusi. Posisi gigi yang tidak benar menyebabkan gigi tersebut menerima seluruh tekanan oklusi sehingga mengakibatkan perubahan-perubahan pada jaringan periodontal.Jaringan periodontal merespon peningkatan tekanan oklusal tersebut dengan beradaptasi dan berdegeneratif, dimana kondisi tersebut masih bersifat reversible ketika trauma dihilangkan. Efek dari tekanan oklusal pada jaringan periodontal sangat bergantung pada arah, durasi dan frekuensi trauma. ${ }^{19}$ 
Menurut De Boever dkk (2004) (dikutip dari Tukak F O, 2013), dalam artikelnya yang berjudul oklusi dan kesehatan periodontal menyatakan bahwa traumatik oklusi primer pada periodontal yang sehat tidak menyebabkan inflamasi(tekanan ortodonti dan jiggling force). Pada jiggling force tekanan yang terlalu besar dapat menyebabkan kegoyangan gigi penyangga pada pasien yang menggunakan gigi tiruan. ${ }^{5}$ Tahun 2008 Bhola dkk (dikutip dari Tukak F O, 2013), mengemukakan bahwa tidak terlihat adanya jawaban yang jelas terhadap peran traumatik oklusi dalam penyakit periodontal. Traumatik oklusi tidak memicu terjadinya gingivitis atau periodontitis, oklusi merupakan faktor sekunder dalam proses terjadinya periodontitis. ${ }^{5}$

Tahun 2006 Bernhard dkk melakukan penelitian cross-sectional pada 2980 pasien dengan rata-rata umur 40.Penelitian ini mencari hubungan antara kontak oklusi yang buruk dengan kedalaman poket dan kehilangan perlekatan.Hasilnya menunjukan bahwa non-working balancing contact memiliki hasil yang signifikan dengan terjadinya kehilangan perlekatan dan kedalaman poket. Working side hanya signifikan dengan terjadinya kehilangan perlekatan, dan tidak signifikan dengan terjadinya kedalaman poket. Tahun 2011 Branschofsky, dkk (dikutip dari Meredyk K, 2013) menemukan adanya hubungan yang positif antara traumatik oklusi dan periodontitis.Penelitian ini dilakukan pada 288 pasien yang mengalami periodontitis.Ditemukan bahwa pasien yang mengalami sejumlah prematur kontak memiliki korelasi dengan kehilangan perlekatan. Pasien dengan periodontitis yang parah memiliki jumlah prematur kontak yang lebih banyak. $^{15}$

Masih banyaknya pemakai GTSL yang memiliki $\mathrm{OH}$ buruk menunjukkan bahwa pasien tidak mengetahui dan tidak mengerti cara membersihkan gigi tiruan dan rongga mulut, serta kurangnya kesadaran pasien akan kebersihan rongga mulut. Masih banyaknya pasien yang mengalami traumatik oklusi menunjukkan masih tidak tepatnya pemeriksaan traumatik oklusi yang dilakukan, sehingga masih ditemukan banyak pemakai GTSL yang mengalami traumatik oklusi.

\section{DAFTAR PUSTAKA}

1. Bratu E, Bratu D, Antonie S. Classification Systems For Partial Edentulous. Oral Health and Dental Management in the Black Sea Countries. 2007; 6(4)

2. Carr AB, Brown DT. Mc Craken's Removable Partial Prosthodontics $12^{\text {th }}$ ed., Missouri: ELSEVIER MOSBY, 2011

3. Abfraction E. The Glossary of Prosthodontic Terms. The Journal of Prosthetic Dentistry. 2005; 94(1): 10-92

4. Klineberg I, Jagger R. Occlusion and Clinical Practice An Evidence-Based Approach. Egypt: Egy Dental, 2004.

5. Tulak F O. Peranan Trauma Oklusi Terhadap Teradinya Periodontitis. Jurnal E-Gigi. 2013; 1(2)
6. Newman M G, Takei H H, Klokkevold P R. Caranzza's Clinical Periodontology $11^{\text {th }} \mathrm{ed}$., Singapore: ELSEVIER SAUNDERS, 2012

7. Bathia S. Periodontics Revisited. New Delhi: Jaypee Brothers Medical Publishers 2011.

8. McCullock A J. Making Occlusion Work : I. Terminology, Occlusal Assessment and Recording. Dental Update. 2003; 30: 150-157

9. Babu R R, Nayar SV. Occlusion Indicators: A Review. The Journal Of Indian Prosthodontic Society. 2007; 7(4): 170-174

10. Mir S N, Choudhary A, Jagadeesh HG. Occlusal Indicators - Chasing Blue Marks? : A Review. TMU J. DENT. 2014; 1(3): 92-95

11. Panigrahi D, Satpathy A, Patil A, Patel G. Occlusion And Occlusal Indicating Materials. International Journal Of Applied Dental Sciences. 2015; 1(4): 23-26

12. Sharma A, Rahul GR, Poduval ST, Shetty K, Gupta B, Rajora V. History Of Materials Used For Recording Static And Dynamic Occlusal Contact Marks: A Literature Review. J Clin Exp Dent. 2013; 5(1): 48-53

13. Qadeer S. The Limitatios Of Traditional NonDigital Occlusal Indicators When Compared To The T-Scan Computerized Occlusal Analysis Technology. In: Kerstein RB. Handbook of Research On Computerized Occlusal Analysis Technology Applications In Dental Medicine, United States of America: Medical Information Sciences REFERENCES, 2015: 36-64

14. Kerstein RB, Radke J. Occlucion Clinician Accurracy When Subjectively Interpreting Articulating Paper Markings. The Journal OfCraniomandibular And Sleep Practice. 2014; 32(1): 13-23

15. Meredyk K, Janicka J K, Gora M N. The Effect of Occlusal Loading on The Periodontal Tisue. A Literature Riview. Part I - Occlusion and Periodontitis. Dental Medical Problems. 2015; 52(2): 215-221

16. Jayasingha R M, Tilakaratne A, Amarasena N, dkk. Impact of Marginal Contact of Removable Acrylic Partial Dentures on Periodontal Parameters. International Journal of Research In Medical and Health Sciences. 2013; 1(3).

17. Feier I, Onisel D, Onisel D. The Plurivalence of The Interpretation of Correlation Between Plaque Score and Bleeding Score. Journal of Romanian Medical Dentistry. 2009; 13(1)

18. Armitage G C. Periodontal Diagnose and Classification of Periodontal Disease. Periodontaology 2000. 2004; 34: 9-21

19. Borges R N, Arantes B M, Vieira D F, dkk. Occlusal Adjustment in The Treatment of Primary traumatic Injury. Stomatos. 2011; 17(33): 71-77. 